\title{
Is Economic Integration Between Developing Countries a Singular Process?
}

\author{
Salif Koné \\ University of Cocody
}

\begin{abstract}
This paper examines the economic integration processes among developing countries and developed nations. It looks into the possible existence of a general theory of economic integration and the reflection is carried out on three levels. The first is theoretical even normative, analyzing the concept of economic integration in various fields. The next is descriptive, which is based on the presentation of the initiatives (past and present) of economic integration. Finally, there is comparative where two main results are established. First is that the characteristics of the processes of economic integration are sufficiently flexible to reflect at the same time the processes of economic integration between developing countries and those between developed countries. Second is that economic integration is seen as a phenomenon with multiple dimensions and shapes and also as a process and the product of this process.
\end{abstract}

JEL Classifications: F15, Y40, Y80

Key Words: Economic Integration, Political Dimensions, Social Dimensions, Cultural Dimensions, Developing Countries

\footnotetext{
* Corresponding Author: Salif Koné; Teacher and Researcher in CIRES, University of Cocody, 08 BP 1295 Abidjan 08, Cote d'Ivoire, salifkon@yahoo.fr.
} 


\section{Introduction}

A renewal movement of the economic integration has been under way around the world since the early 1990s. Meanwhile, the economic policies in favor of a successful insertion of the developing countries into the global economy based on a comprehensive regional economic integration has become numerous. ${ }^{1}$ Moreover, Jean Coussy (2001) sees in this phenomenon "the exploitation of regional integration for political purposes."

Paradoxically, there are more and more voices which rise to proclaim the uniqueness of the processes of economic integration between developing countries given the nature of their actions and their earnings. However, the level of development of the countries is considered as one even the main determinant of the economic integration. Obviously, the general observation of the failure of the almost generalized economic integration initiatives between the developing countries of the first wave compared to the success of the European Union as well as the poor performances of the current initiatives of integration between the developing countries militate in favor of such a thesis. To use the regional economic integration as an instrument of insertion into the global economy and its development in all regions of the world ${ }^{2}$ militates in favor of a universalist conception. In fact, such policy adheres to the view that the rationality of economic integration is that the reduction of the trade barriers constitutes a way to rationalize the economies of the partner countries in order to increase all economic flows, services, direct investments, and financial capitals. In other words, regional economic integration is an effective instrument of insertion for national economies into the global economy.

In fact, in the extensive literature regarding economic integration, two different approaches to the analysis of this process are distinguished: universalism and differentiation by level of development. For the universalists, it is possible to determine the general conditions of improvement of the well-being applicable to any type of economic integration. From the pioneer analysis of Jacob Viner (1950), these analyses remain as essential elements of the condition for improving the welfare of the partner countries as a result of economic integration, which exhibits the superiority of the effects of "trade creation" on "trade diversion."

For the proponents of the differentiation of analyses depending on the level of development of the member countries, such a condition could not be applied to the processes of economic integration involving only developing countries due to the weaknesses and the rigidities of their economic structures.

\footnotetext{
1 This increase in power of the regional integration as an instrument of insertion into a global economy appears through various initiatives: the future economic partnership agreements between the European Union and the ACP countries regionalized, the support of the UNCTAD in favor of south-south cooperation, the bases of the North American Free Trade Agreement (NAFTA), the new directions of the regional integration initiatives between developing countries (ASEAN, ASEAN +1, ASEAN+3, UEMOA, ECOWAS, CEMA, COMESA, SADC, MERCOSUR, etc.).

${ }^{2}$ There is no region of the world which does not follow this revival of the economic integration movement. For verification, see Fiorentino, Verdeja, and Toqueboeuf (2006).
} 
But the analyses of these latter approaches can be divided into two currents according to their conclusions. For the first ones, these weaknesses and rigidities of the economic structures of the developing countries militate in favor of the complete inefficiency of an economic integration between these countries. Consequently, they recommend a vertical integration at the level of nations, namely the north-south integration (Melo (de), at al., 1993; Venables, 1999 et 2000). For the others, on the contrary, the weaknesses and rigidities of the structures of developing economies mean that the profits that they can expect from them are important because the largest profits of the economic integration are based on the long run (CooperMassell, 1965a et b; Foroutan, 1993, etc.).

Behind these oppositions are emerging epistemological and methodological debates about the understanding, the analysis, and the practice of economic integration. From the adopted approach depends the answers given to many crucial issues, in particular if regional economic integration can be effectively used as an instrument of insertion in a globalized economy. If so, how? Beyond that, the question which arises is to know if the process of economic integration between developing countries is particular.

In fact, what is in question here is the reducing character of the standard economic analyses concerning economic integration. These analyses indeed fail to take into account all the complexity and diversity of the economic integration processes. Thus, they cannot properly highlight and synthesize the entirety of advantages and inconveniences of an economic integration process. The complexity of the phenomenon of economic integration and the confusion it causes on the level of economic analysis are aptly summarized by Jean Coussy (1996).

The objective of this work is to show that despite such appearances, a comprehensive conceptual framework can be built for a general theory of economic integration that can relate the various developed analyses regardless of the level of development of partner countries. To do this, we use a semantic analysis of the concept of economic integration with references to past and current experiences. The challenge of this paper is to allow a reconciling of works and results which may appear to be contradictory.

In this perspective, the continuation of this work understands three sections: the first analyzes the contours of the concept of economic integration, the second presents the methods, approaches, and forms of economic integration, and the third analyzes its dimensions.

\section{The Field of Economic Integration}

Economic integration appears as an ambiguous concept. According to François Perroux (1958), "In the hierarchy of obscure words and economic discussions that clutter our language, the term integration occupies a good position." 
The contours of the concept of economic integration are blurred because they are multiple and they go beyond purely economic considerations. To know the nature of it, it is advisable to apprehend it within a global framework. It is necessary to make a semantic analysis of the topic of integration to define its dimensions and scopes on one hand and to distinguish its approaches, methods, and forms on the other.

The need for a semantic reading is also due to the finding of a profusion of terms to describe the phenomenon of regional economic integration. In fact, in the literature of terms, regionalization, regionalism, regional economic integration, regional economic cooperation, regional economic areas, regional economic blocks, regional trade agreements, etc., all refer to the phenomenon of regional economic integration and more generally economic integration. How is it possible? When does each of these terms refer to the same object? Are these terms in their purpose and dimension also valid for the same phenomenon when it is applied to developing countries? This section will attempt to answer these questions through a semantic analysis on the concept of economic integration.

\section{A. Integration and Cooperation}

There is often confusion between the concept of integration and that of cooperation. However, from a semantic point of view, these two concepts do not merge. First, in economy, the concept of cooperation conveys the idea of reversibility whereas that of integration refers to the idea of irreversibility. If the process which emanates from the first can be stopped at any time by one of the partners, that emanating from the second cannot be, at least in theory. From a political and institutional point of view, the concept of cooperation refers to the implementation of intergovernmental institutions while that of integration to that of supranational institutions. From an operational perspective, finally, cooperation conveys the idea of voluntary collective actions whereas integration the idea of united action sought by a unique higher authority.

In this sense, economic integration cannot be done without economic, political, and institutional cooperation. Economic integration requires both irreversible and reversible actions, intergovernmental and supranational institutions, decisions and voluntary collective action and unification.

In this perspective, the success of the European Union is that it has managed to combine the cooperation and the integration from which it derives a rigorous but flexible approach. We can notice that when this balance was upset in its integrative approach, it felt the effects in the progression (e.g, evolution of the European Construction over the period 1966-1985 or still the rejection of the project of the European Constitution by countries as France). Similarly the internal difficulties faced by the ASEAN ${ }^{3}$ following the financial crisis in Southeast Asia in 1997

\footnotetext{
${ }^{3}$ Association of Southern-East Asian Nations
} 
can be explained by a too strong cooperative tendency.

It should be emphasized that in the field of international relations, cooperation can be understood as a common approach by the pooling of resources and efforts for the achievement of these common objectives. Under these conditions, the concept of cooperation is broader than that of the economic integration that it includes.

Thus, at a broader level, the concepts of cooperation and integration indicate the same phenomenon. However, from an economic point of view, the concept of integration privileges the interpretations in terms of irreversible actions. In this perspective, the concept of economic integration cannot adopt different definitions when it is implemented by developing countries or by developed countries. The concept of integration in its base is not defined, indeed, in relation to the nature of the actors.

\section{B. Economic Integration and Politic Integration}

The concepts of economic integration and political integration can be sometimes confused due to the proximity of their fields. But they differ in their frames, objectives, and mechanisms. Economic integration has for framework the economy. It consists of the reduction even the removal of the trade barriers between the partners. It primarily seeks to liberalize the trade exchanges between partners in order to improve the overall efficiency and/or to develop the economies of the partner countries. Politic integration has for frame the management of the power or the administration of the city. In its international dimension, it consists of transferring the exclusive rights of state-nations to a broader political entity. Thus, it aims at building more effective political entities. However, an economic integration cannot be done without a political integration. First, for its proper performance, any economic integration needs a total or a partial transfer of sovereignty (exclusive rights of state-nations) to a community institution, a wider

political economic entity. Second, political integration may be the final form of economic integration.

This is the case of the European Union in search of a political constitution that would supplement its regional construction. Such a construction requires to determine the nature of the governmental structure as well as its implementation. The literature distinguishes three possible structures of government: unitary, federal, and confederate. Third the ultimate goal of economic integration is to find a solution to international conflicts by improving the well-being of the population. However, it should be emphasized that political integration can be done without passing by economic integration.

At this level, a specificity of the economic integration processes between the developing countries cannot be justified. From a semantic point of view, the definition of economic integration does not rely on the nature of the actors. 


\section{Economic Integration and Firm Integration}

There is often confusion between the integration in the sphere of the industrial organization and the integration in the economic sphere in general. Both types of economic integration are different with regard to the object they are attached. The notion of integration in the area of the industrial organization is attached to the firms and to the industries. In the industry area, it refers to the groupings of activities within the same firm or the same group. Here, it is synonymous with concentration, mergers, cartels, and acquisitions of holdings, among others. There are two types as well: horizontal integration and vertical integration. On the contrary, economic integration in the economic area in general is attached to territory.

These two types of economic integration are not mutually exclusive. In fact, the entire operation of the regrouping firms and industries is one of the facets of economic integration. Territorial integration, for which the companies are the main actors, is one of the forms of economic integration. According to the theories of the new geographical economy, economic integration, because it changes the relationships between the centrifugal and centripetal forces, is likely to cause the concentration of economic activities in fewer places. In short, it implies the involvement of the producers. At this price it allows the rationalization of the production structures in a given region. The logic of this rationalization of the production applied across the world and intensified gives today what is known as the globalization of business. The mechanisms of the globalization of the production by the enterprises are the same for the developing and developed countries. However, the eligibility conditions and the profits each can expect from the other may be different depending on its level of development. But that is not enough to make specific the process undergone by developing countries.

\section{National Economic Integration and International Economic Integration}

The concept of region is often a source of ambiguity to understand the concept of economic integration as it can be understood at three levels: sub-national, supranational, international. In the first case, economic integration is carried out within the borders of a nation-state. It is then existing to create, to improve, and to increase the interconnections among the different sectors or economic activities within a country. But the concept of economic integration that concerns us is international because it involves several countries. Its international character makes all the difference as it introduces concerns and new complexities, sometimes specific as the distribution of the costs and the profits or the nature of the community institutions. From this perspective, the international integration includes the last two levels of understanding of the concept of a region.

It should be noted that any successful economic integration requires the taking into account of national considerations. The improvement of the interconnections of the various economic 
sectors in each member state and the development of the poorest member countries remain some of the major objectives of any economic integration. Ignoring them could damage the proper evolution of any economic integration process given the differences of levels and capacities of development of the national regions and the nations. Thus, a comprehensive understanding of the economic integration phenomenon includes the taking into account of its effects on the structure and the interconnection of the economic activities at the sub-national level.

From this point of view also, the tendency to create an industrial center and an agricultural periphery is a common element of the economic integration processes between developing countries and the integration processes between industrialized countries. The integration processes between industrialized countries and developing countries create similar effects. The reasoned history of the worldwide economic integration initiatives proves it. Europe is known for its hot banana and the North American Free Trade Agreement (NAFTA) is renowned not only for exceptional concentration of industrial activities in relatively more developed countries, but also around their capital.

\section{E. International Economic Integration and Global Economic Integration}

The international nature of economic integration constitutes another source of ambiguity. International economic integration can either refer to insertion in the global economy or involve the approximation of a subset of countries. The main difference between these two types of international economic integration is that the second is discriminatory while the first is universal. As it is actually, multilateral economic integration, still called global or universal, has entered a more accelerated phase called globalization. This one is characterized by very high reduced economic distances and a growing interdependence of the national economies. Due to the difference of their main nature, they often play opposite, especially in the political approaches of the discriminatory economic integration. In particular, the question is whether international economic integration will affect the progression of multilateral integration due to its discriminatory nature.

Thus, the evolution of the ASEAN and the new orientations in Africa and in Latin America show that these two types of integration are not fundamentally incompatible for the developing countries. In Africa and in Latin America these initiatives are used as anchors for a better insertion into the global economy. Furthermore, the question arises on the effects of the formation of the regional economic blocks about the nature, the meaning and the optimality of the world exchanges. Many studies have been dedicated to this relation. Although there is no unanimous conclusion, these studies highlight the importance of the potentially beneficial effects of a regional economic integration for a successful insertion into the global economy, from where the reasons are regionalism and regionalization. In the same way, whereas the European Union was built away from the global competition, its construction has not basically 
challenged the foundations of the multilateral trade liberalization. Quite the contrary, it pushes even its partners in Africa, Caribbean, and the Pacific (ACP) to open up more in order to better integrate the global economy.

This justifies partially, within the framework of the Cotonou Agreement, the opening of negotiations for the implementation of new trade agreements promoting development, in conformity with the rules of the World Trade Organization (WTO), while maintaining privileged relationship between Europe and the ACP states. Thus, in terms of their relationship with globalization, the processes of economic integration between developing countries and those between developed countries retain strong similarities.

\section{F. Economic Integration, Regional Integration, Regionalization or Regionalism}

One of the sources of ambiguity in the concept of economic integration is related to the confusion among economic integration, regional economic integration, regionalism, and regionalization. Indeed, authors have made a habit not to distinguish these four concepts of economic integration. It is yet advisable to do it insofar as the determinants of the second and the third concepts are based on the concept of proximity whereas it is only an option for the first one. Belonging to the same region is the main vector to create the conditions necessary for the achievement of goals for regional integration.

Quite as in the case of regional integration, regionalization differs from economic integration because it is based on the concept of proximity, unlike the latter. However, the concept of proximity is different within the framework of the regionalization of regional economic integration. Indeed, the concept of proximity that contains the regionalization includes and exceeds that of proximity in the case of regional integration. The proximity involved in regionalization is not only geographical (transport costs) but cultural, historical, linguistic, even political. It also means being similar in political systems, living standards, or trade policies.

Despite these differences, economic integration excludes neither regional integration nor regionalization. Indeed, almost all of the economic integration initiatives are of regional type since the end of the Second World War. The same applies to economic integration and regionalization overlap. Regionalization as a process of construction of a commercial or socioeconomic and political community is the regional version of the international economic integration whose regional integration constitutes the prerequisite. It is this approach of economic integration, regional integration, and regionalization that seems to highlight the African countries through the NEPAD, the African Union, ASEAN, ASEAN +1, ASEAN + 2,

\footnotetext{
${ }^{4}$ New Partnership for Africa's Development
} 
ASEAN +3, the MERCOSUR, the SIA (Sustainability Impact Assessement) of the European Union, etc.

In this perspective, the economic integration processes between the developing countries are not different. The same phenomena are found on both sides with some differences.

\section{G. Real Economic Integration and Monetary Integration}

It is advisable to distinguish the real economic integration of the monetary integration. Often regarded as a counterpart of economic integration, monetary integration can be independently undertaken. The WAMU ${ }^{5}$ has not only preceded the WAEMU $^{6}$ but it has been built independently of the Economic Commission for Western Africa (ECWA). According to Laporte, the sequence "first economic integration, then monetary integration" is less effective than the reverse sequence for the developing countries, at least.

But it is better to understand monetary integration as a necessary complement to the success of any advanced real economic integration. From this perspective, the opportunity to adopt a single currency leads to debate. According to Salin (1995), for example, such a decision can be justified only by a semantic confusion between "market integration" and "producer integration." However, the adoption of a single currency is defended even if it is only through the adoption of a single currency since January $1^{\text {st }}, 2002$ by the European Union and the resilience of this currency. In fact, the issue of the order of integration is not of fundamental relevance. The literature distinguishes four forms of monetary integration: the unstructured unions for exchange rate, the structured unions for exchange rate, the integral monetary unions, and the monetary areas (Cobham et Robson; 1996). The first describes the situation in which countries are integrating their markets of capital but maintaining distinct national currencies. Their currencies are convertible to each other according to a fixed exchange rate. The second describes the situation in which countries are integrating their markets of capital, keeping the separate national currencies, pooling their reserves, and having separate central banks but being closely coordinated. The integral monetary unions denote a situation in which countries adopt a single currency, have a central bank and the same organs of intervention on the exchange markets. The last denotes a situation in which countries link their currencies to those of developed countries. In a comprehensive approach to economic integration, the first three forms of monetary integration are the complement to an advanced level. However, the analysis of initiatives (past and present) of economic integration shows that none of the four forms of monetary integration described here above is the prerogative of any particular type of economic integration. If the construction of the European Union on one hand and the construction of the WAEMU in West

\footnotetext{
${ }^{5}$ West Africa Monetary Union

${ }^{6}$ West Africa Economic and Monetary Union
} 
Africa and the Central African Economic and Monetary Community (CEMAC) in Central Africa on the other hand tend to confirm the assertion of Laporte, it is not the same with the economic integration initiatives in Latin America and in Southeast Asia. The economic integration initiatives in Latin America and in Southeast Asia have not been backed to a monetary integration in their respective area. Moreover, this reversal has not made the economic integration initiatives more effective in West Africa and in Central Africa than in Southeast Asia or in Latin America. Thus, here again, the processes of economic integration between developing countries or between developed countries are not basically different.

\section{The Methods, Approaches, and Forms of Economic Integration}

The insufficient characterization of the employed terms and the classifications of the economic integration initiatives have created some confusion in the suggested typologies, tending to strengthen the thesis of the specificity of the economic integration processes between developing countries. The proliferation of writings and thoughts on the subject often gives the impression, especially among the "developmentalists" that the economic integration between developing countries is basically differentiated from that between developed countries in its methods, approaches, and forms.

\section{A. The Approaches and Methods of Economic Integration}

In reference to the operating process of the economies, there are only two antagonistic conceptions of economic integration: economic integration through markets and economic integration through plan. The first takes place between countries with market economies and, thus, draws an essential part from the market concept. This is the case of the initiatives in Africa, in Asia, in Western Europe, and in America (North and South). The second, also known as integration through production covers only countries with centrally planned economies and draws an essential part from communist ideology. This is the case of the Council for Mutual Economic Assistance (COMECON). Contrary to what some writings may suggest, the economic integration initiatives between developing countries do not differ from those between developed countries. Most often, the economic integration initiatives, if not colonial remnants, are the transpositions of the western models, with the notable exception of the ASEAN from 1967 to 1992.

In reference to the particular adopted methods for trade liberalization, the literature offers a 
range of typologies in two ways (Tinbergen, 1965; Lawrence, 1996; Hugon, 2001), three ways (Robson, 1984; Deblock, 2006), and five ways (Hugon, 2002).

These typologies can run opposite one another. Also, in all cases, the existence of different approaches or methods of integration cannot be used to justify the specific processes of the economic integration between developing countries compared to those between developed countries. To that, there are two main reasons. Firstly such a vision is reducing the complexity of these initiatives. Indeed, each of the economic integration initiatives combines features contained in, at least, tow approaches, here above mentioned. This applies to the European Union often presented as the archetypal of the liberal economic integration, yet it combines the features of these three approaches. Just look at the Common Agricultural Policy (CAP) adopted to protect the European farmers. Secondly, the economic integration initiatives between developing countries do not always have the basic characteristics of the same approaches. Thus, the economic integration initiatives between the developing countries of the $60 \mathrm{~s}$ and the 70s are often opposed to each other with reference to this classification. The ASEAN and the $\mathrm{SADCC}^{7}$ are considered as the archetypes of sectoral integration, the Andean Pact as that of voluntary integration, and the initiatives of the sub-Saharan Africa as archetypes of global economic integration. Their differences in efficiency are then explained by the specificities of their approaches.

\section{B. Economic Integration Forms: a Product or a Process?}

Regarding the forms of economic integration, the conventional analyses suggest a typology in five elements since Balassa (1961): the free trade area, the Customs Union, the Common Market, the Economic Union, and the Economic and Monetary Union. The free trade area refers to a situation in which countries agree to eliminate the tariff and non-tariff barriers on their mutual exchanges while preserving the freedom of their trade policy with the rest of the world. The Customs Union refers to the situation in which not only countries agree to eliminate the tariff and non-tariff barriers on their mutual exchanges but also adopt a common external tariff as well as common trade policies towards the rest of the world. The Common Market refers to the situation in which goods and the services move freely between the partner countries with common policies and external tariffs with the rest of the world, letting production factors move freely (Capital and Labor). The Economic Union or the Economic and Social Union refers to the situation in which countries decide a) the free movement of goods and services b) the free movement of the production factors c) the implementation of common trade policies and common external tariffs with the rest of the world d) the implementation of harmonized or common social policies, and e) the coordination of their macroeconomic policies including, in particular,

${ }^{7}$ SADCC : Southern Africa Development Conference Co-operation. 
monetary and budgetary policies. Finally, the Economic and Monetary Union leads to the implementation of common monetary and financial policies as well as the creation of a single currency between partners. At this stage, the different markets of the partner countries are included whether those of the markets for goods and services, labor, or capital and finances.

This typology has a problem of interpretation because two definitions are opposed. The first describes the different forms of economic integration (in term of end) and is a structuralist vision of it. In this case, economic integration is viewed, analyzed, and designed as a finished product. It implies that countries, if they wish, may choose to realize their integration under one or the other of the described forms. Under these conditions, the methods of trade liberalization consist of the adoption of chains of economic and sometimes political measures. A reading of economic integration experiments shows that developing countries, as a whole, except perhaps those in Southeast Asia, have adopted this interpretation. Thus in West Africa for instance, the goals of the different economic integration initiatives have given the following evolution: The objective of the first initiative (the $\mathrm{WACU}^{8}$ created in 1962) was the implementation of a free trade area. The second initiative (the CUWAS $^{9}$ created in 1966 to replace the WACU failed) was the implementation of a Customs Union. After which, the objective of the ECWA, created in 1972 to replace the CUWAS, another failure, was the creation of a Common Market. The latest initiative is the WAEMU (created in 1994), which aims to create, ultimately, a single market with a single currency and all conditions of harmonization and unification of the monetary, financial, fiscal, budgetary, and social policies. It has already a single central bank (CBWAS: Central Bank of West African States) because it has replaced the ECWA (a failure) and the WAMU.

The second interpretation describes the different stages of economic integration. In this case, it is viewed, analyzed, and understood as a process. It is here where the functionalist vision of economic integration lies. Under these conditions, the methods of trade liberalization are economic and political measures to be gradually implemented according to a certain order to increase their effectiveness. This conception of economic integration seems to have guided the construction of the European Union. The progression of the latter and the subsequent modifications of the initial objectives of the Treaty of Rome can be interpreted in this direction. The objective of the Treaty of Rome is the implementation among its six members of a common market within a maximum of twelve years. Its progression rests on its members respecting this objective as a whole. Thus, from a free trade area between 1957-1967, it became an economic and monetary union on January $1^{\text {st }}, 2002$ with the adoption of a single currency while passing respectively the stages of a Customs Union (1967-1985), a Common Market (1995-1993), and a Single Market (1993-2002). The drafting of a project of European Constitution marks clearly the evolution of the European Union towards a more political phase.

\footnotetext{
${ }^{8}$ West Africa Customs Union

${ }^{9}$ Customs Union for West African States
} 
Considering the results of the experiments of the economic integration between the developing countries and those between the European countries, the first interpretation seems unsatisfactory. Whereas the early experiments of the developing countries (except perhaps the ASEAN) can be regarded as failures, those of the Western Europe are a success. However, it seems inappropriate to oppose these two interpretations. Economic integration is both a process and a stage.

In fact, there exists in the literature many other typologies of the forms for international economic integration. These typologies differ either because they are made under different angles or because they use different criteria. It arises from the analysis of these different typologies that they are useful at different levels, but they fail by the impossibility to define clearly the contours of the different possible forms of economic integration. From this point of view, the Balassa's typology remains the most relevant. Moreover, the economic integration considered both as a process and a state would allow to soften the contours of the different forms of economic integration as defined by Balassa. The particular interest for these new typologies is that it seeks to integrate into the analyses of economic integration for political considerations. For that, these analyses attempt to establish a clear relationship between economic analyses and international relations. However, economic integration goes beyond purely economic and political considerations and above all it is not just a regional phenomenon. These typologies which tend to question Balassa's typology, including that by Regnault, fail by the fact that they consider each component as a fixed part in time and space by the contents of the contract or the agreement which defines the contours, once and for all. This is a misunderstanding of interpretation which reduces the scope of this typology. The economic integration must be viewed, designed, and applied as a process and its product. Every form of the economic integration may be both the culmination of a process and one of the different stages of a continuous process. Each step can be also a product as the ultimate goal of the movements of link between the partner countries (e.g., the European Free Trade Association). But the economic integration may seek to deepen the interdependence between the partner countries in building a strong socioeconomic and political community, guided by a common development culture focusing on particular aspects. ${ }^{10}$ It is these diverse realities, flexible and sometimes difficult to understand, which the analyses of the third section of this document are trying to establish.

\section{The Dimensions of Economic Integration}

Economic integration is a systemic phenomenon insofar as it is certainly an economic phe-

\footnotetext{
${ }^{10}$ Söderbaum emphasizes the need to understand the new process of the regional integration under the angle of the building of social institutions, particularly.
} 
nomenon, but it is also a political, social, cultural, and historical phenomenon.

\section{A. The Political Dimensions}

Beyond the institutional and legal structures that require any economic integration, this integration results and contributes to the political game (in terms of power management) at the national and international level.

Indeed, on the national as on the international level, the economic integration process can be analyzed as the result of the political actors of the committed countries. The politicoeconomic models highlight this dimension of any process of economic integration. Introduced by Johnson, the politico-economic models (models of endogenous protection) fall into five categories, according to the approach that they adopt to make endogenous the economic policies $^{11}$ : a) the approaches by the functions of determination of the tariffs b) the approaches by the functions of political pressure (egoistic or not) c) the approaches of the median voter $\mathrm{d}$ ) the approaches of contribution to the electoral campaigns, and e) the approaches of contribution to the economic policies. These models connect the construction of the economic blocks with the process of internal distribution of the power with the nature of the power distribution within the involved country, the electoral process of the countries, or with the nature of the electoral process or decision-making. In short, for these models, the motivations for building an economic block are also determined by the political powers available to the producers and the consumers as well as by the nature of the political interactions and distribution of the power within the countries concerned.

At the international level, economic integration can be analyzed under the angle of the construction of regional economic blocks. From this point of view, there are many arguments in favor of a close link between the economic integration process on one hand and the distribution and the dynamics of the power in the world on the other. Considered indeed under this angle, the issues of security, of regional stability, or of strategic positioning become relevant (Deblock, 2005). Despite their diversities, these arguments can be summarized as follows. On the security of the States, by considering non-dissociable the positioning of each state in the global economy and by taking into account the fact that this positioning, in turn, depends on the capacity of these economies to remain dynamic and competitive, the integration becomes a strategic action. This tends to prove the two following facts. In the context of the regional integration process, there is an increasingly strong trend to set up mechanisms of prevention and management of conflicts. At the world level and/or at the regional level, the same transpires for texts regarding economic integration initiatives.

These aspects of the political dimensions of the economic integration processes are valid for the economic integration processes between developed countries and developing countries.

\footnotetext{
${ }^{11}$ See Rodrik, Dani (1995) for a detailed presentation of this literature.
} 
Indeed, whether it be in the integration process of the European Union, Latin America, Southeast Asia, or Africa, political dimensions tend to weigh heavily.

Moreover, the political dimensions of an economic integration are not limited to its political effects; they also stem from national, regional, or global political processes. ${ }^{12}$ The revival of the movement of economic integration, its nature, and its new direction do not save any part of the world today. This state of facts is, partly, the consequence of the disappearance of the bipolar world. Without the end of the Cold War politics, it is understood that countries with formerly planned economies would have undoubtedly never followed such a movement. Yet it is the case, today, for many of them. Moreover, the new directions of the integration processes between developing countries tend to emphasize trade liberalization, to put in background the ideas having led to the adoption of the import-substitution policies. It also probably would not have been possible if the bipolarization of the world continued. In the case of ASEAN, for example, from 1967 to 1990 , it adopted an integration policy whose main objective was the acceleration of the economic growth, the social progress, and the cultural development of the region in order, ultimately, to strengthen the nations of the region. To do this, it has emphasized a political approach and a regional construction based on neutrality so that the constraining aspects of an economic integration (removal of the trade barriers, the free movement of the persons and the capital, the coordination of the national economies and the trade policies, and the transfer of sovereignty to supranational institutions) are not tackled thereby, consistently defending a policy of neutrality between the opposing blocks of East and West. But since 1992, after the end of the bipolar world, the ASEAN launched out in a deepened policy of economic integration with the aim of implementing a Customs Union by 2015.

Similar arguments can be developed with the European economic integration with a parallel between the lessons drawn by the outbreak of the Second World War and its economic, financial, and human consequences, having the political ideology that the United States of America developed with the "European Recovery Program" or with the "Marshall Plan" the pressure to decolonize. The costs of the Second World War for the Western countries ended up convincing their populations and their political authorities that the solution to their development problems could not be in the war but in a peaceful coexistence. In this context, what better way to emphasize the interdependence of their economies but by a continuous process that could even lead to a political integration? A political idea which stands behind the Marshall Plan.

Similar arguments can be developed for South America by referring to the ideas of Simon de Bolivar who dreamed to make Latin America a federal state as soon as its liberalization of European colonization. Thus, two phenomena mark the first initiatives of economic integration in Latin America after the Second World War. On the one hand, they tend to create a regional economic entity covering all Latin America while the logic of their construction is widely based on the import-substitution policies. This reflects two strong political ideas in the region at

\footnotetext{
${ }^{12}$ See Jean COUSSY (2001) for an excellent presentation with a historical approach of this reality.
} 
the time namely Pan-Americanism and development by the industries of substitution, according to the theories of the leaders from ECLAC (Economic Commission for Latin America), such as Raul Prebrish.

Finally, similar arguments can be also developed on the economic integration processes in Africa by analyzing the political contours of the independences and the rejection of the Pan-Africanism ideology of Kwame Nkrumah by the African and international community. Nkrumah dreamed of seeing the building of a unified cultural and political awareness in Africa for its emancipation and for a radical break with the colonial power. But his political idea was disapproved by both the African political leaders of the independences and by the political authorities in the Western countries. Thus, at the beginning of the independences, the idea of political emancipation pushing the continuity of the relations between Europe and Africa dominated the political landscape. This state of facts allows to explain partly three major characteristics of the economic integration initiatives in Africa. First, these initiatives are mostly based on the vestiges of the colonization. Second, they are varied and they lead to a kind of balkanization-grouping. Finally, these initiatives have developed the policy of importsubstitution at the regional and sub-regional scales.

Also, whether the political dimensions of the economic integration act as effects, elements, or results of the processes, they are present both in the processes of economic integration between developed countries and in developing countries.

\section{B. The Social Dimensions}

Economic integration, as economic policy, has important social repercussions for the populations of the partner countries. In addition, it participates to the construction of new social norms.

The social effects of the economic integration processes are many and can be either direct or indirect. Economic integration, regional or not, has a functionalist or a structural approach because it requires the mutual trade liberalization of the partner countries, leading to the restructuring of the economic activities in each country. From there, any economic integration, at least in the short run, causes effects of employment and income loss for some sectors of the economies of the partner countries. Moreover, because of its potential effects of concentration of economic activities in fewer places, any economic integration can create inequality in the income distribution between partner countries and even within each nation.

The indirect social effects of economic integration are due to the dominance of liberal ideology on interventionism. In fact, economic integration needs to be based on texts whose implementation requires a modification of the texts of social protection. The process of economic integration is primarily a trade liberalization process. In other words, it is a commitment to reduce, an event to eliminate all barriers to the mutual trade between the partner countries. 
Since this action is liberal, it is therefore, more and less, the ideology of "let make, let go" and "everything will be better for all." This translates, in practice, to the decline of use of political power for the purposes of modification, redistribution, or correction of the economic system.

These social effects of economic integration remain, however, a reality for everyone, even if they differ according to the development level of the partner countries. In fact, if the management of the social policy at the community level as a whole dimension of the economic integration process is late in Europe ${ }^{13}$ and has not been sufficient in the eyes of the French population for the adoption of a European constitution, it will be a major concern in the economic integration processes between developing countries from the start. This is what justifies the implementation of structural funds for the development in almost all economic integration initiatives in Africa, at the South of Sahara. It explains the creation of the Andean Group and is the core of the ASEAN construction.

To contain these social effects and to better manage them across the community, every step towards the economic integration initiatives produces social norms inducing the implementation of social rights alongside economic rights, as described by Arnaud (1997) for the European Union and as claimed by Peter Bakvis (2000) for the continental integration in America.

A favorable social environment is an important element for any successful economic integration process, as taught by the successes of the promoters of the ASEAN or also by those of the European Union. The construction of a favorable psycho-sociological framework was, indeed, one of the most important results of the regional construction of the ASEAN between 1967 and 1990. The main objective of the ASEAN during this time was to accelerate economic growth, progress, and social development by promoting peace and regional stability. From this perspective, at the political and social level, the first success of the ASEAN was the creation of a community and regional spirit. Its second success was to have been able to function independently from the rest of the world while benefiting from the financial support of the United States. The ASEAN is an association founded by the countries of the region, apart from the influences of external powers and operating without bias in the division of the world in two antagonistic blocks. The member states of the ASEAN affirmed their common will and thus their goals were dealt with. The third political success of the ASEAN has been the consolidation of its member states as nations. The political cooperation envisaged by the ASEAN had a dual focus: internal and external. The internal consolidation of its member states has effected the strengthening of a regional and community awareness. Furthermore, the relative success of the ASEAN is attributed to the weight of China's financial and commercial networks in the region and to its important role in the Asiatic trade development, following certain authors as to what makes the ASEAN a reticular integration.

The adoption of the Treaty of Rome, creating the European Economic Community, was made possible thanks to a favorable social and psychological environment. The changes of the

\footnotetext{
${ }^{13}$ According to Jean-Louis Arnaud (1997), it dates in Europe in the late 1980s.
} 
European national societies, following the Second World War and its psychological impacts, ended up convincing the Europeans that the consolidation of their different nations could be done by peaceful means. This state of affairs required a nesting of their economies through an increased interdependence to reduce any risk of new fatal and devastating conflicts.

Thus, economic integration processes cannot be distinguished by the level of development of the partners because what is important for a general theory is not the nature of economic integration's social effects but its existence.

\section{The Cultural Dimensions}

Culture in its broadest sense remains an important determinant of any economic integration process because it is, at the same time, a prerequisite, an element, and a consequence.

The linguistic, administrative, political, and ethnic proximities or distances can be a reason for success (UE and ASEAN) or for failure (Africa, south of Sahara) in the economic integration processes. In the case of the European Union, the success of the European integration is sometimes explained by strong linguistic, administrative, political proximity and a lack of ethnic division. Similarly, the success of the ASEAN between 1967 and 1990 is very often explained by (we have noted above) the heavy weight of the Chinese economic and financial networks in the region. In the case of the ASEAN, linguistic, political, and ethnic proximities prevail. On the contrary, in Africa at the south of Sahara, the difficulties encountered in the integration initiatives are explained by strong ethnic differences, making chronically unstable the political situation and reinforcing administrative and legal differences inherited from colonization. In short, a marked convergence of the nature and symbol of economic integration and the men acting between them is not only conducive to the birth of an economic integration process but also is a condition for its success.

Moreover, the economic integration processes are sources of creation of new cultures that originate between developing countries or developed countries. To achieve objectives, economic integration requires the practice of free trade (involving goods, services, capital, and people), which modifies, at the same time, the relationships of the populations in the space since the national spaces tend to be extended to those of the partner countries, the relationship of the men, as well as their visions of the beautiful, the good, and the true. This principle is a part of the foundation of economic integration.

\section{The Historical Dimensions}

Besides the fact that any economic integration is an element of the history of the partner 
countries and the world as a whole, it is also the result of the historical process of the world, the regions, and the partner countries individually, thereby producing History. Thus, economic integration is the sum of the historical development of the economic, cultural, social, and political relationships which justify or not the creation of an economic integration process, as well as its shape and its progression.

The recent history of Western Europe is determined by the two world wars, their social, psychological, cultural, and political consequences. This history is also determined by American intervention on the military, political, and economical level. It is marked by the bipolarization of the world at the end of the Second World War and the need even the obligation of decolonization. It is the particular arrangement of these phenomena that explains the coexistence of the European Coal and Steel Community (ECSC), the European Economic Community (EEC), and the Continental European Division (CED) and the narrow political, economic, financial, and cultural relationships retained by the European countries and their ex-colonies, particularly in Africa. The relations are even institutionalized in the Treaty of Rome in its Article 31.

The violent history of colonization and European decolonization, the violent story of the Japanese domination in the Asian countries during the Second World War, and the violence of the confrontations between the communist China and the Americans and their allies have determined the choice of the countries of the ASEAN for a position of political neutrality, the non-proliferation of weapons of mass destruction, the reinforcement of the state-nations, and the funding from the United States for their development. Similarly, the history of the evolution of their social culture dominated by a strong attachment to the family group and constrained by the assertion and the prominence of individuals also explains the specific terms of seeking stability, progress, and social development through the creation of a regional and community awareness.

The violent colonial history of Africa with its psychological consequences, the incomplete decolonization, and especially the evolution of the African societies and the cultures show the inability of the Africans to find common cultural and social funds, explaining today the multiplicity and the inefficiency of the economic integration processes in Africa at the south of Sahara. Indeed, the domination in African societies of colonialism in all its sectors makes Africa one of the few regions today that imports models of integration and economic development without trying to adapt them to its realities nor to seek to have the capacity for them. In short, history remains an important part of any economic integration process, whether this process is born between developing countries or developed ones.

\section{Conclusion}

Of the previous analysis, we can recall Hugon (2001) by adopting the concept that indus- 
trialized countries as developing countries are engaged "in (economic) integration processes whose shapes range from the sectoral co-operations to political unions with transfers of sovereignty. The regionalization (which is the support) is multifaceted. It is more or less supported by institutions and by regional trade agreements (RTAs) or "de jure regionalism." It can result, however, from practices of actors constituting trade, financial, cultural, technological, and political networks in regional areas (de facto regionalism). It can also result from a fragmentation of the global space taking in strategies of segmentation by transnational actors.

But what is also retained from this analysis is the existence of two levels of "multidimensionality" of economic integration. On the first is a multiplicity of the dimensions: economic, political, historical, social, and cultural. On the second is a multiplicity of the forms of economic integration in each of its dimensions: economic, financial, monetary, institutional, sectoral, etc.

So in the building of a general theory of economic integration, only the multiplicity of general dimension has to be considered. Thus, in a fruitful approach, any economic integration process must take into account the existence of these two levels of "multidimensionality." Consequently, no specificity of these processes between developing countries is fundamental because any level of characterization of the phenomenon could be seized in these dimensions.

We retain, furthermore, that the economic integration is both a process and the product of this process. From these two characters are born the generality of the process of any economic integration. Those are at the source of two types of relations on the determinants of economic integration. The first is a circular causal relationship between the different dimensions of the economic integration. The second is a dynamic interaction between the process of integration and each one of its dimensions by the particular characteristics of the adopted forms.

As a whole, the processes of any economic integration are the same. They cross similar stages and all require favorable initial conditions. In fact, the economic integration processes between developing countries and those of the integration between industrialized countries differ only by their starting points. While the integration processes in industrialized countries take place within developed frameworks, those of the developing countries must ensure those. However, the dynamics which are necessary for economic integration as an effective development strategy seem to be also necessary for the industrialized countries. The time is an important factor to justify the existence of any type of economic integration, given the nature of its important profits over the long run. But this does not mean that these processes differ as a result of their development levels in the distribution of the costs and the benefits of their integration process.

This vision of the economic integration as a phenomenon with dimensions and multiple forms and as a process and a product of this process is summarized in the diagram above in Appendix 1 .

Received 01 July 2011, Revised 31 May 2012, Accepted 21 June 2012 


\section{References}

Alésina, A. and R. Perroti (2004) 'The European Union: a politically incorrect view', Journal of Economic Perspectives, Winter, pp. 26-48.

Alésina, A. I. Angeloni, and F. Etro (2005) “'International Unions '”, American Economic Review, N95, pp. 602-615.

Arnaud, J-L. (1997) "L’Europe sociale : histoire et état des lieux", Etudes et Recherches n`3, Groupement d'Etudes et de Recherches Notre Europe.

Bakvis, P. (2000) "La dimension sociale de l'intégration continentale", ISUMA, printemps, 2000.

Balassa, B. (1961) Theory of Economic Integration, Irwin-Illinois, Allen and Unwin.

Cobham, D. et P. Robson (1996) 'Intégration monétaire à la lumière du débat européen" , dans Réal Lavergne, Intégration et coopération régionales en Afrique de l'Ouest, Paris-Ottawa, KARTHALA-CRDI, chapitre 11, pp. 277-297.

Cooper C. A. and B.F. Massell (1965a) "A New Look at Customs Unions Theory", The Economic Journal, pp.742-747.

Cooper C. A. and B.F. Massell (1965b) 'Toward a General Theory of Customs Unions for Developing Countries"', Journal of Political Economy, vol.73,ํ5, pp.461-476.

Coussy, J. (1996) "Causes économiques et imaginaires économiques de la régionalisation", Cultures \& Conflits n ${ }^{\circ} 21-22$, pp.347-372.

Coussy, J. (2001) "Économie politique des intégrations régionales: une approche historique"', Mondes en Développement, Tome 29-115/116, pp.15-26

Deblock C. (2005) 'Régionalisme économique et mondialisation : que nous apprennes les théories ?', Cahier de recherche $N^{\circ}$ 05-07, GRIC.

Deblock C. (2006) "Régionalisme, arrangements institutionnels hybrides et gouvernance à la carte", Multilatéralisme régional $N^{\circ} 4$, Symposium de haut niveau sur les dimensions sociales des processus d'intégration régionale.

Deblock Christian , B. Dorval, et M. Rioux (2003) “Zone de libre-échange des Amériques et intégration en profondeur asymétrique", chap. 22, dans Regnault H. , Intégration euro-méditerranéenne et stratégies économiques, l'Harmattan, Collection "Emploi, Industrie et Territoire".

Deblock, C. et H. Regnault (2005) "Les enjeux théoriques de la reconnexion Nord-Sud", at http://web.univpau.fr/RECHERCHE/GDRI-EMMA/Rinos/32_Nord-Sud_Intro.pdf.

Fiorentino R., L. Verdeja and C. Toqueboeuf (2006) ' The Changing Landscape of Regional Trade Agreements: 2006 Update"', WTO, Discussion Paper $\mathrm{N}^{\circ} 12$.

Foroutan, Faezeh and Land Pritchett (1993) 'Intra-Sub-Saharn African Trade : is it too Little ?", Journal of African economics, vol. 2, pp.74-105.

Hugon, P (2006) "Quel rôle peuvent jouer les organisations d'intégration régionale dans une nouvelle architecture internationale ?", Multilatéralisme régional $N^{\circ} 3$, Symposium de haut niveau sur les dimensions sociales des processus d'intégration régionale.

Hugon, P. (1998) "Les séquences inversées de la régionalisation", Revue Tiers Monde, N¹55, pp 529-555. 
Hugon, P. (2001), Analyse comparative des processus d'intégration économique régionale, étude, Direction Générale de la Coopération Internationale et du Développement, Ministère des Affaires Etrangères, sous la direction de.

Hugon, P. (2002) "Les économies en Développement au regard des Théories de la régionalisation", Revue Tiers Monde, tome 43, pp. 9-24.

Johnson, H. G. (1954) "Optimum Tariffs and Retaliation", Review of Economic Studies 21, pp.142-153.

Kebabdjian G., (2004) 'Economie politique du régionalisme : le cas euro-méditerranéen', Région et Développement N¹9, pp. 151-184.

Krishna, P. (1998) 'Regional and Multilateralism : A Political Economy Approach", The Quarterly Journal of Economics, PP 227-251.

Krugman, P.R. (1991) "Is bilateralism Bad ?", In Elhanan Helpman and Razin eds., International trade and Trade policy, MIT Press, Cambridge (UK), Chapter1.

Krugman, Paul (1995) "Regional Versus Multilateralism : Analytical Notes", Chapter 3 in New Dimensions in Regional Integration, Cambridge University Press.

Krugman, Paul R (1992) 'L'émergence des zones régionales de libre-échange: justifications économiques et politiques"', Problèmes économiques N²289, pp. 18-27.

Laporte, B. (1996) "L'intégration monétaire avant l'intégration commerciale : le cas de l'Afrique de l'Ouest", Revue d'économie du développement, $N^{\circ} 3$, pp. 95-114.

Lawrence, R. Z. (1996) 'Regionalism, Multilateralism, and Deeper Integration", Washington, Brookings Institute; "Emerging Regional Arragements: Building Blocks or Stumbling Blocks?”, dans R. O’Brien, Finance and the International Economy, Vol 5, Londres, Oxford University Press, pp. 22-35

Melo (de), J., C. Montenegro and A. Panagariya (1993) "L'intégration régionale hier et aujourd'hui", Revue d'Économie du Développement, vol 2, pp.7-49.

Perroux, F. (1958) La coexistence pacifique, Paris, PUF, Vol. (1,2 et 3).

Regnault, H. (2005) "Libre-échange Nord-sud et typologies des formes d'internationalisation des économies", Région et Développement, $N^{\circ} 22$, pp.19-38.

Robson, P. (1984) The Economics of International Integration, London, UK, George Allen \&Unwin.

Rodrik, D. (1995) 'Political Economy Of Trade Policy", Chapter 28, Handbook of International Economics, Vol. III, Edited by Grosmman, Gene and Rogoff, K.

Salin, P. (1991) 'Quelles monnaies pour le marché unique européen ?', Revue d'économie politique, vol. 101, pp. 109-126.

Söderbaum, F. (2002) "Rethinking the New Regionalism", at http://www.socsci.auc.dk/institut2/nopsa/arbejdsgruppe23/soederbaum.pdf

Sukup, V. (1987) "L’intégration « volontariste » comme accélérateur du développement. Le pacte andin, une expérience limite qui contredit les théories libérales", Thèse de doctorat de $3^{\text {ème }}$ cycle, Université de Paris III, Sorbonne Nouvelle, Institut de Hautes Études de l'Amérique latine.

Tinbergen, J. (1965) International Economic Integration, $2^{\text {nd }}$ eds, Amsterdam : Elsevier

Venables, Anthony J. (1999) 'Regional Integration Agreements : a Force for Convergence or Divergence ?', conférence ABCDE, Paris juin. 
Venables, Anthony J. (2000) "Les accords d'intégration régionale : facteurs de convergence ou de divergence ?", Revue d'économie du développement, $\mathrm{n}^{\circ}$ 1/2, pp. 227-246.

Viner, J. (1950) The Customs Union Issue, New York : Carnegie Endowment for International Peace. 
Figure 1. Economic Integration Process

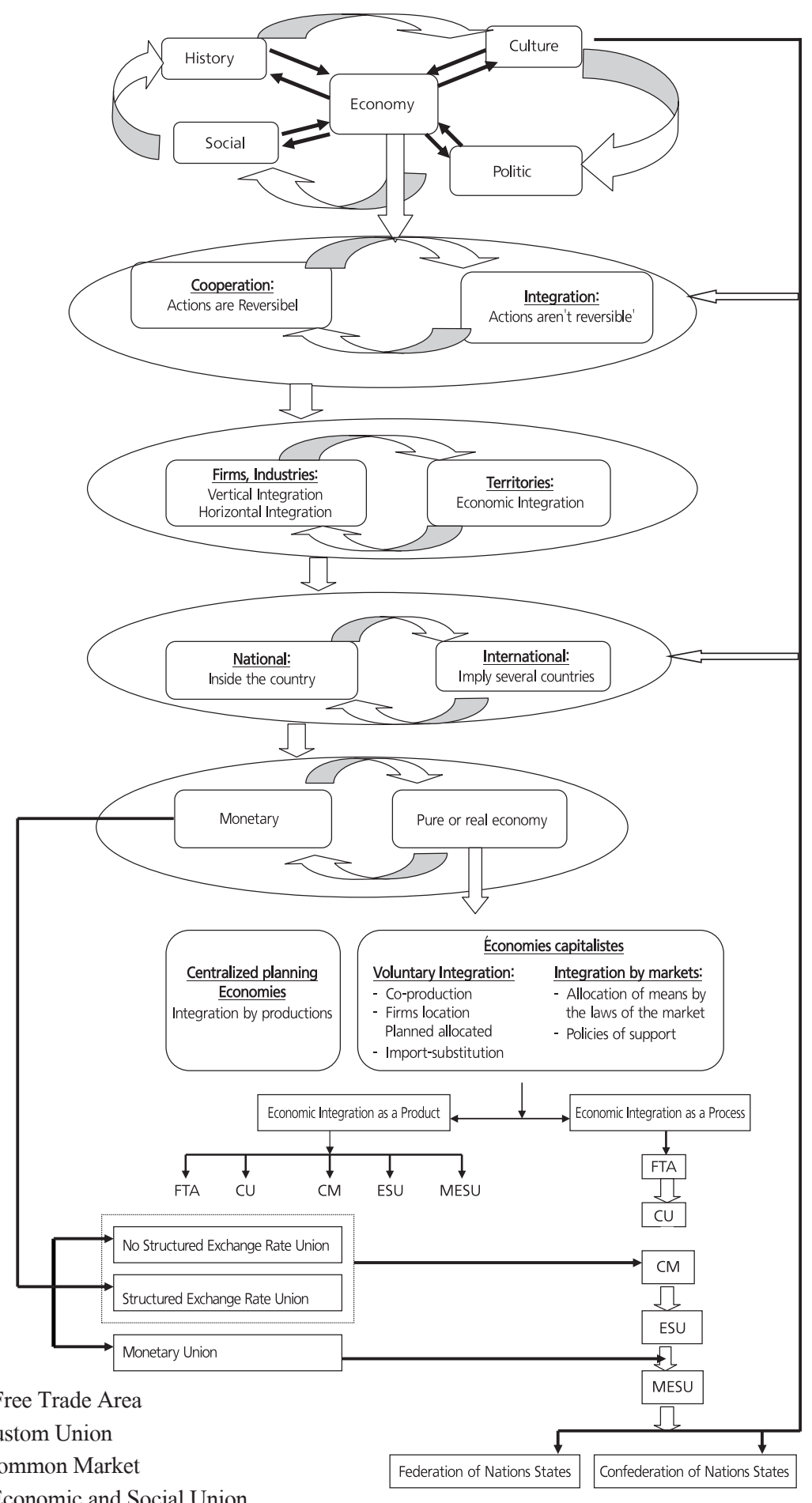

Note: FTA: Free Trade Area

CU: Custom Union

CM: Common Market

ESU: Economic and Social Union

MESU: Monetary, Economic and Social Union 